\title{
Sulfate reduction and formation of a nickel-rich member of the tochilinite group during experimental serpentinization of olivine
}

\author{
TOM MCCOLLOM ${ }^{1}$, TORI HOEHLER ${ }^{2}$, DAVID A. FIKE $^{3}$ \\ AND FRIEDER KLEIN ${ }^{4}$ \\ ${ }^{1}$ University of Colorado \\ ${ }^{2}$ NASA Ames Research Center \\ ${ }^{3}$ Washington University in St Louis \\ ${ }^{4}$ Woods Hole Oceanographic Institution \\ Presenting Author: mccollom@lasp.colorado.edu
}

Seawater sulfate is a potential electron acceptor for microbial communities living beneath the seafloor within serpentinizing environments, providing the sulfate can persist in these systems without being reduced by abiotic processes or precipitated as sulfate minerals. At present, however, the extent to which sulfate is abiotically reduced during serpentinization is poorly known. To investigate this issue, we are performing a series of laboratory experiments reacting olivine with artificial seawater to evaluate sulfate reduction during serpentinization as a function of temperature. At $265^{\circ} \mathrm{C}$, serpentinization of the olivine produced substantial amounts of molecular hydrogen $\left(\mathrm{H}_{2}\right)$ but no evidence for sulfate reduction was found after almost seven months of reaction. At $300^{\circ} \mathrm{C}$ and $328^{\circ} \mathrm{C}$, generation of $\mathrm{H}_{2}$ was also observed but at amounts that decreased over time and that were substantially less than observed in sulfate-free serpentinization experiments performed at the same conditions. These observations are consistent with reduction of dissolved sulfate by $\mathrm{H}_{2}$ to $\mathrm{H}_{2} \mathrm{~S}$ (which was observed in small amounts in the $300^{\circ} \mathrm{C}$ and $328^{\circ} \mathrm{C}$ experiments). The extent of sulfate reduction was greater at $328^{\circ} \mathrm{C}$ than at $300^{\circ} \mathrm{C}$, even though $\mathrm{H}_{2}$ concentrations and extent of serpentinization were less. Secondary sulfide minerals formed in the $300^{\circ} \mathrm{C}$ and $328^{\circ} \mathrm{C}$ experiments included Co-rich pentlandite and haapalaite, a Ni-rich member of the tochilinite-valeriite mineral group that consist of a mixture of sulfide and hydroxide layers. To our knowledge, this is the first time that minerals from the tochilinite-valeriite group have been identified in a laboratory serpentinization experiment, and suggest that reduction of seawater sulfate could be one pathway for formation of minerals from this group that have been observed in natural serpentinites. Efforts to place more quantitative constraints on the rates of sulfate reduction in these experiments are underway. 